\title{
A Novel Variable-Frequency Three-Phase Induction Motor Drive System Using Only Three Controlled Switches
}

\author{
Brian A. Welchko and Thomas A. Lipo, Fellow, IEEE
}

\begin{abstract}
This paper presents a novel variable-frequency motor drive system for a three-phase induction machine. In this drive system, the machine is excited by unidirectional stator currents shaped and sequenced such that a rotating air-gap flux is induced so that the machine can operate. Due to the unidirectional nature of the currents, an "inverter" that incorporates only three active, insulated-gate-bipolar-transistor-type switches, and three freewheeling diodes can synthesize them. The drive system requires an asymmetric induction machine that can easily be obtained by externally rewiring a motor with a dual-wound stator. The inverter is supplied by a single-phase input via a voltage-doubler diode rectifier; hence, it can be operated with residential service. In this paper, theoretical control methods are presented and both simulation and experimental results are provided proving the validity of the proposed drive system.
\end{abstract}

Index Terms-Induction machine, inverter, motor drive, threeswitch, unipolar.

\section{INTRODUCTION}

V ARIABLE-SPEED drives have found widespread use in industrial applications. However, in the household and consumer market their adoption has been sparse. A significant reason that electronic drives have not penetrated the consumer market is their high cost. In a retail marketplace, consumers tend to put little emphasis on "total cost of ownership," including energy costs, and tend to put more emphasis on the initial purchase price and inherent features of the product. In the heating, ventilating, and air-conditioning (HVAC) market, controlling the airflow with an adjustable-speed drive would allow overall system optimization that could significantly reduce energy consumption [1]. Without an adjustable-speed drive, the remainder of the system needs to be oversized, and standby and startup/shutdown losses are significant. In addition to increased efficiency, an adjustable-speed drive used in this application has the potential to hold a tighter temperature band since airflow will always be circulating. It can also be quieter since the system will not be plagued with the starting and

Paper IPCSD 01-045, presented at the 2000 Industry Applications Society Annual Meeting, Rome, Italy, October 8-12, and approved for publication in the IEEE TRANSACTIONS ON INDUSTRY APPLICATIONS by the Industrial Drives Committee of the IEEE Industry Applications Society. Manuscript submitted for review May 1, 2000 and released for publication July 25, 2001. This work was supported by the Center for Power Electronics Systems (CPES). CPES is a National Science Foundation Engineering Research Center under Award EEC9731677.

The authors are with the Department of Electrical and Computer Engineering, University of Wisconsin, Madison, WI 53706 USA (e-mail welchko@cae.wisc.edu; lipo@engr.wisc.edu).

Publisher Item Identifier S 0093-9994(01)09704-3.

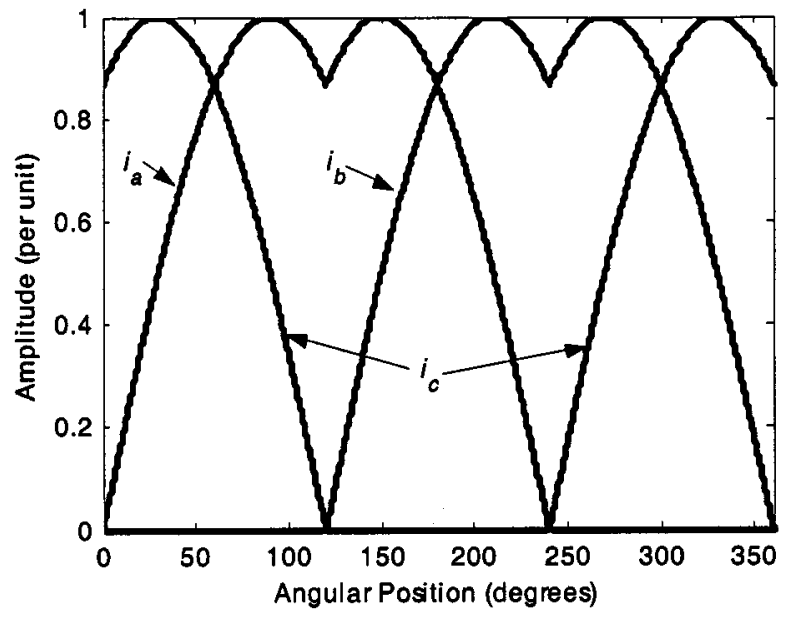

Fig. 1. Proposed motor phase currents.

stopping noise of both the motor and compressor, as they will operate continuously in a reduced capacity.

This paper proposes a new adjustable-speed motor drive system containing a three-phase induction machine and an electronic drive. This paper also proposes a novel current control method for an induction machine that allows for the motor to be speed and/or torque controlled by only three active insulated-gate-bipolar-transistor (IGBT)-type switches. A similar system and control method was proposed in [2], but the system is not physically realizable. This proposed topology with the control method is significant because it has a lower parts count than traditional motor drives. The voltage-source inverter with six switches is standard practice and the use of four switches has also been demonstrated [3]. In addition to the novel topology, the system is focused around a common three-phase induction machine with trivial wiring modifications. As a result, the proposed system achieves full speed control, and maintains good efficiency, at a low comparative cost. The combination of increased performance and lower initial cost will allow for further penetration of adjustable-speed drives into the consumer marketplace.

\section{Current Control Method}

A novel closed-loop current control method is proposed for a three-phase induction machine. The currents are unidirectional in nature, as shown in Fig. 1. The harmonic spectrum of the phase currents (to the 15th) is given in Fig. 2. Since these phase currents are not sinusoidal and do not sum to zero, access to the 


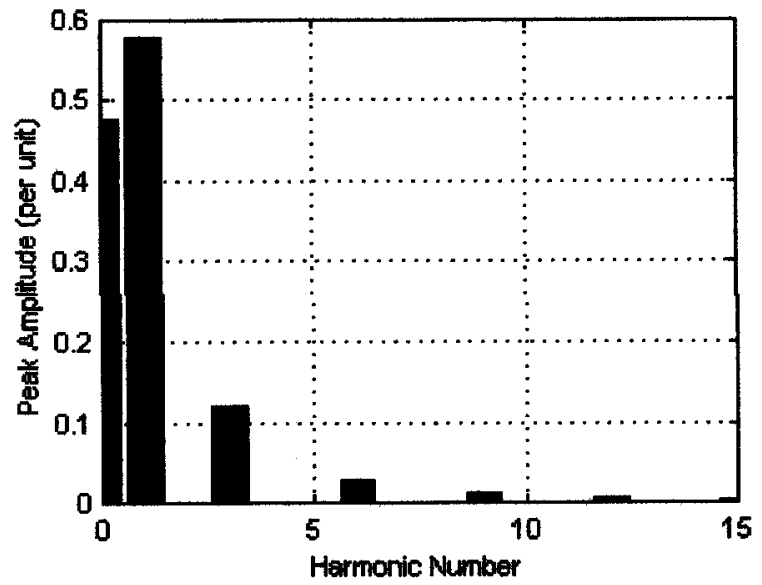

Fig. 2. Phase current harmonic spectrum.

TABLE I

Phase CurRent Definitions Over AN Electrical CyCle

\begin{tabular}{c|r|r|r}
\hline \multirow{2}{*}{ Current } & \multicolumn{3}{|c}{ Angular Position } \\
\cline { 2 - 4 } & $0<\omega t \leq 120^{\circ}$ & $120<\omega t \leq 240^{\circ}$ & $240<\omega t \leq 360^{\circ}$ \\
\hline Phase $a\left(i_{a}\right)$ & $\mathrm{I}_{\max } \sin (\omega t)$ & $\mathrm{I}_{\max } \sin (\omega t-\pi / 3)$ & 0 \\
\hline Phase $b\left(i_{b}\right)$ & 0 & $\mathrm{I}_{\max } \sin (\omega t-2 \pi / 3)$ & $-\mathrm{I}_{\max } \sin (\omega t)$ \\
\hline Phase $c\left(i_{c}\right)$ & $\mathrm{I}_{\max } \sin (\omega t+\pi / 3)$ & 0 & $\mathrm{I}_{\max } \sin (\omega t-4 \pi / 3)$ \\
\hline
\end{tabular}

stator neutral point of the machine is required in order to have full control over each of the individual phase currents.

The phase currents are composed of a fundamental component, a dc offset, and triplen harmonics. Only two phases are conducting at once and each phase conducts for $240^{\circ}$ of an electrical cycle. Table I defines the piecewise combination of sinusoids that compose the phase currents. The dc offset and triplen harmonics are scaled such that the maximum value of the fundamental component can be obtained for a given amplitude of a unidirectional or unipolarity current-source excitation.

For an induction machine with a sufficient number of stator slots, lumped sinusoidally distributed stator inductances can be assumed and space harmonics can be neglected. Furthermore, it is assumed that switching frequency harmonics in the phase currents that would be present in any practical inverter are negligibly small. For this case, the stator current vector which governs the air-gap MMF [4], is given as

$$
\tilde{I}=\frac{2}{3}\left[i_{a s}+i_{b s} \cos \left(120^{\circ}\right)+i_{c s} \cos \left(-120^{\circ}\right)\right] .
$$

Upon substitution and simplification of currents given by Table I into (1), the stator current vector as seen by the $a-s$ axis is

$$
\tilde{I}=\frac{\sqrt{3}}{3} I_{\max } \sin \left(\omega t-30^{\circ}\right) .
$$

Equation (2) shows that the proposed current control method for a three-phase induction motor with stator neutral access creates a stator current vector of constant amplitude that is rotating with a constant angular frequency $\omega$. As a result, this will in- duce an air-gap MMF of constant amplitude rotating at the same frequency. Along with a squirrel-cage rotor, the conditions of constant torque production have been satisfied. Essentially, due to the spatial sinusoidal distribution of the stator windings, the effects of the nonfundamental components of the currents are canceled out. Therefore, the unipolar current source excitation shown in Fig. 1 is better thought of as the combination of a fundamental component and a zero-sequence component rather than a fundamental component and a dc component.

Fig. 3 shows graphically how a constant amplitude rotating stator current vector can be formed with only two currents as opposed to three for normal sinusoidal operation. Currents in the figure correspond to those shown in Fig. 1.

Table II compares the proposed waveshape to that of the well-known sinusoidal operation. As seen in the table, the stator copper losses will be 2.4 times larger than for sinusoidal operation. This comes from the fact that, for the unipolar phase current excitation, the phase current amplitude needs to be $\sqrt{3}$ to produce the same fundamental component as a unit amplitude sine-wave excitation would produce. In rms terms, for a fixed flux value, the unipolar currents will have a value 1.55 times that of sinusoidal operation. While the unipolar excitation requires a larger phase current to produce a given flux, the extra losses that result occur only in the stator windings. The rotor and iron losses remain unchanged when compared to sinusoidal operation since the air-gap flux has a constant amplitude and velocity. These additional losses, while undesirable, are concentrated in the stator where it is possible to increase cooling so that the excess heat can be removed.

For small $(<1 \mathrm{hp})$ general-purpose induction machines, three-phase machines typically have an efficiency of about $75 \%$ while single-phase machines typically have efficiencies around $60 \%$. Therefore, it is anticipated that operating a three-phase induction machine with unipolar currents will yield an efficiency approximately equal to that of a single-phase machine. Since this topology is suited to replace single-phase drive systems in the residential market, efficiency improvements would still be possible through process efficiency (pumps, blowers, etc.) changes afforded by variable-speed operation [1].

\section{IDEAL IMPLEMENTATION}

An ideal implementation of a converter to implement the proposed method is shown in Fig. 4. This figure clearly shows the phase leg structure consisting of an IGBT or MOSFET and a diode. This is a shoot-through-free leg structure since there is no danger of shorting out the dc bus via inadvertent switching. Shown as a solid line is the current path when the switch is conducting. When on, a positive voltage $V_{b 2}$ is applied across the phase of the motor. This will serve to increase the current in the phase. Shown as a dashed line is the current path when the diode is conducting. When the switch turns off, the diode in turn, is forced on, and a reverse voltage $V_{b 1}$ is applied across the phase. This will serve to drive the current in the phase down. As a result of the two different bus potentials that can be applied across each phase of the motor, the current in the phase can be controlled to be any positive value and the current shapes given by the proposed method can be obtained. 


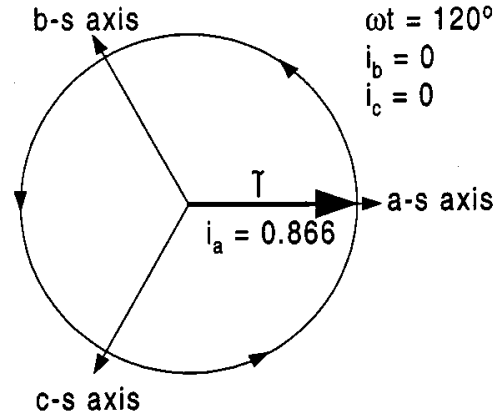

(a)

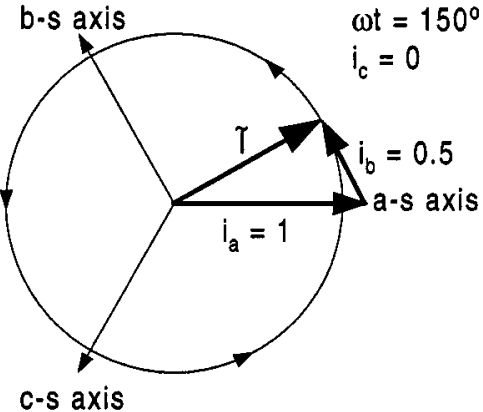

(b)

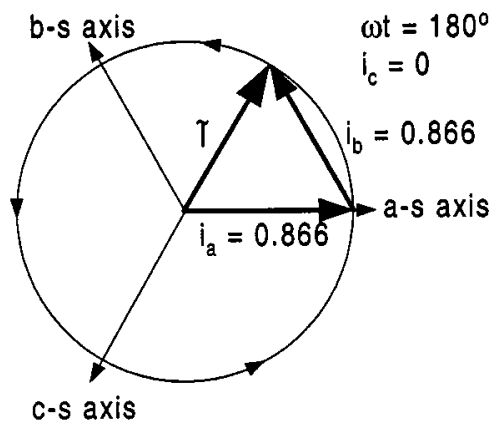

(c)

Fig. 3. Rotating constant amplitude stator current vector formed by two currents.

TABLE II

COMPARISON OF THE Proposed CURRENT Shape AND SinusoidAl OPERATION

\begin{tabular}{l|c|c|c|c}
\hline \multicolumn{1}{c|}{ Waveform } & $\begin{array}{c}\text { RMS Value } \\
\text { (p.u.) }\end{array}$ & $\begin{array}{c}\text { RMS Fundamental } \\
\text { (p.u.) }\end{array}$ & $\begin{array}{c}\text { DC Value } \\
\text { (p.u.) }\end{array}$ & $\begin{array}{c}\text { Relative Copper Losses for a } \\
\text { Given Flux Level }\end{array}$ \\
\hline Sine wave (amplitude 1) & 0.707 & 0.707 & 0 & 1.0 \\
\hline Proposed wave-shape (amplitude 1) & 0.631 & 0.408 & 0.447 & 2.4 \\
\hline
\end{tabular}

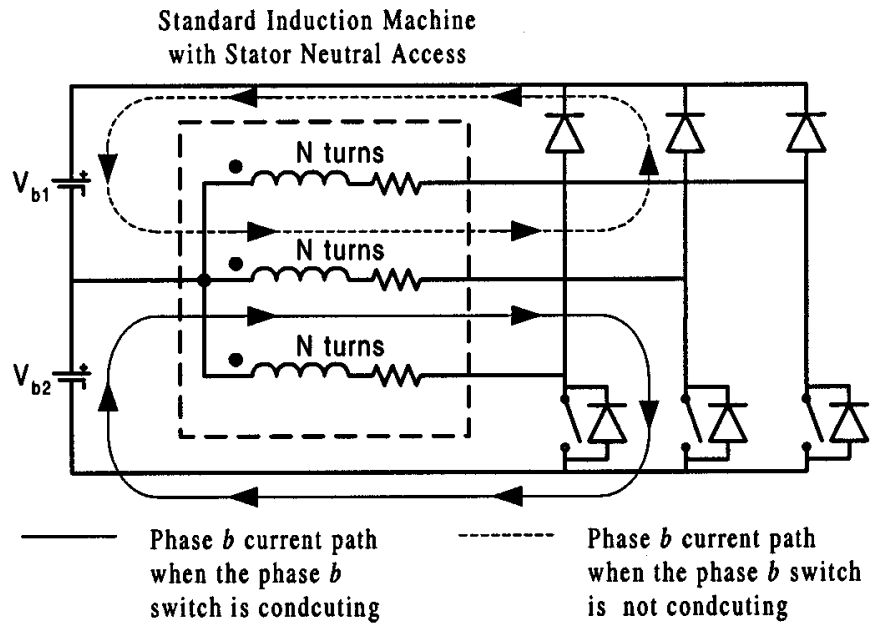

Fig. 4. Ideal implementation of the proposed induction machine current control method.

While simple and symmetric, the ideal implementation as shown in Fig. 4 cannot be implemented with a passive dc link. Visual inspection of this circuit reveals that the upper dc-link supply $V_{b 1}$ does not have a discharge path. For all of the possible switching states, it is either inactive, or absorbing energy from the motor. No passive source such as a battery or a capacitor supplied by a diode rectifier can sustain a constant charging condition. While it would be possible to create such a link with an active ac-to-dc front-end converter, the reduction in the number of active switches, and cost savings, obtained from using this drive topology would be lost.

\section{PRACTICAL IMPLEMENTATION}

The practical implementation of the proposed current control method is shown in Fig. 5. From the power converter, or "inverter" standpoint, the only difference between this and the ideal implementation of Fig. 4 is the flipping of one of the phase

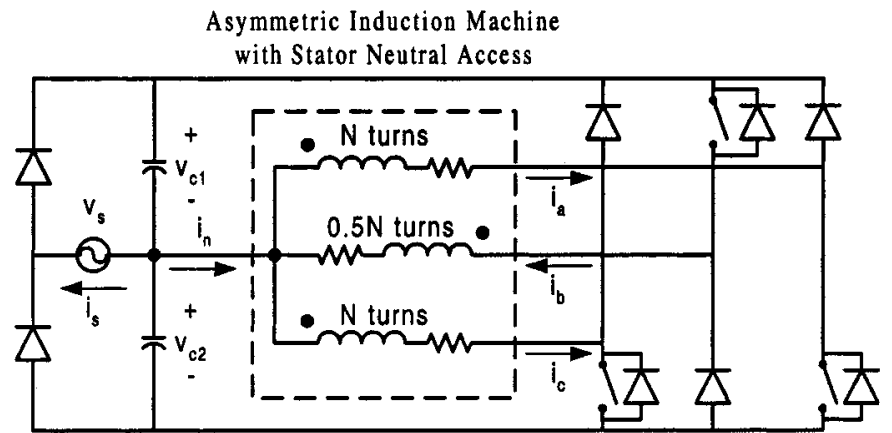

Fig. 5. Proposed drive topology for unipolar current control of a three-phase induction machine.

legs. Phase $b$ is now actively connected to the upper dc link while phases $a$ and $c$ are still actively connected to the lower dc link. The choice of flipping phase $b$ is arbitrary. However, the arrangement of having one phase connected to the upper bus and two to the lower bus is advantageous over having one connected to the lower bus and two to the upper bus because then only one floating gate drive power supply is required.

In this circuit, the split-rail dc link is obtained from a voltagedoubler diode rectifier. This represents the lowest parts count solution since it has only two diodes. Improved power factor and input harmonic spectrum could be obtained if the diodes were replaced with a pulsewidth modulation (PWM) boost converter or other power-factor-correction circuit to supply the split dc bus.

The induction machine used is a nonstandard three-phase machine, although it is easily obtained. Many induction machines are wound with two pairs of stator windings so that the windings can be configured (externally) to operate off either of two specified voltages. Fig. 6(a) shows the lumped stator windings of a dual winding machine that has been configured to operate on the lower rated voltage. Fig. 6(b) shows how an asymmetric machine was obtained for unidirectional current control. The two 


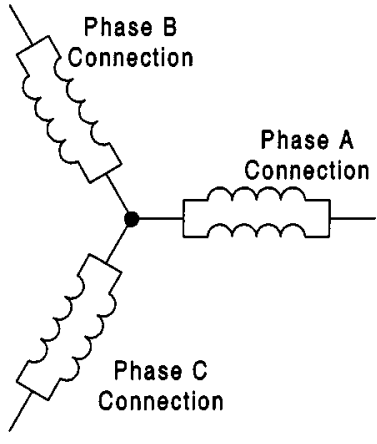

(a)

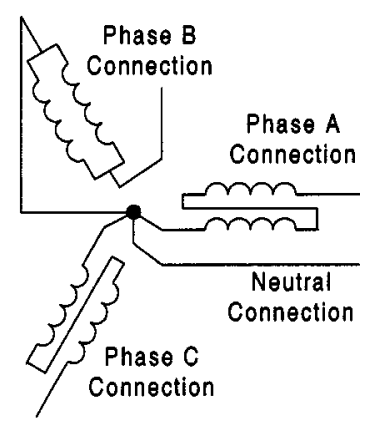

(b)
Fig. 6. Wiring modifications of (a) a dual stator winding machine to obtain (b) the asymmetric machine.

windings of phase $b$ are connected in parallel for low-voltage operation and phases $a$ and $c$ are connected in series for highvoltage operation. Connecting the opposite end of the windings to the neutral point reverses the magnetic polarity of phase $b$. Finally, the neutral point is brought out of the machine so it can be used by this motor drive.

Since the changes required in this machine can be achieved with only wiring connection modifications, it is anticipated that for the high-volume residential applications that are targeted, the cost penalty associated with producing this machine would be modest. From a materials standpoint, the machine is identical, except for the addition of a small length of wire for the neutral connection.

To compensate for the reverse in polarity of the windings of phase $b$, the direction of current flow from the motor drive in this phase is reversed, as shown in Fig. 5. The reversal of current negates the reverse of the polarity of the winding so each of the three phases contributes an MMF that is rotating in the same direction. The phase- $b$ windings, connected in parallel, effectively create a winding with half the number of stator turns than that of phases $a$ and $c$. In order to create the same contribution to the air-gap MMF, the current in phase $b$ needs to be double in magnitude to that of phases $a$ and $c$. By connecting the phase- $b$ windings in parallel, the impedance of this phase is reduced by a factor of four when compared to the impedance of phases $a$ and $c$ due to their series connection. As a result, the double amplitude of current in phase $b$ is achieved with only half the voltage required to produce the nominal current in phases $a$ and $c$.

With phase $b$ connected to the upper bus drawing twice the current of phases $a$ and $c$ which are connected to the lower bus, the current that is flowing in the stator neutral wire of the motor, shown as $i_{n}$ in Fig. 5, is a sinusoidal quantity. As a result, the amount of energy removed from each of the capacitors by the three phases is balanced and, on average, is a discharge path. The source diodes create a charge path and the result is a stable dc-link system.

Fig. 7 shows the phase currents for the practical implementation of the three-switch drive system with unipolar currents. The currents are shown with the polarities defined in Fig. 5. This figure clearly shows that the neutral current is a sinusoidal quantity with an amplitude of $\sqrt{3}$ times that of phases $a$ and $c$. This low-frequency current will flow through the dc-bus capacitors and needs to be considered during the link design as an addi-

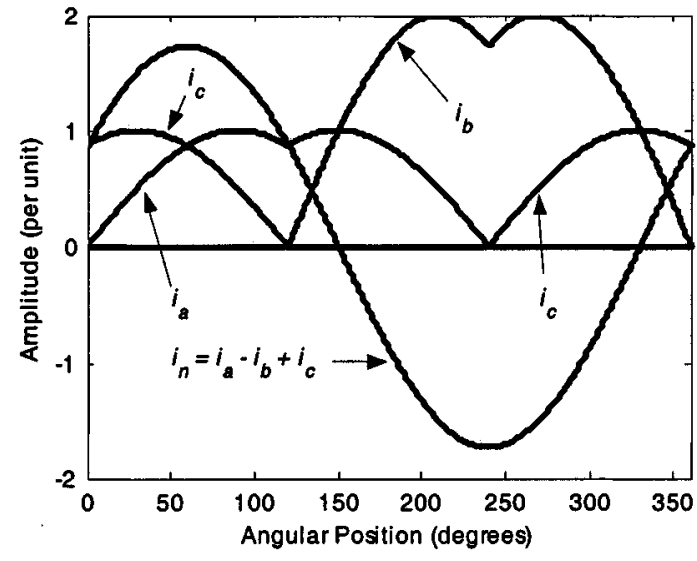

Fig. 7. Practical implementation of the phase currents showing the neutral current.

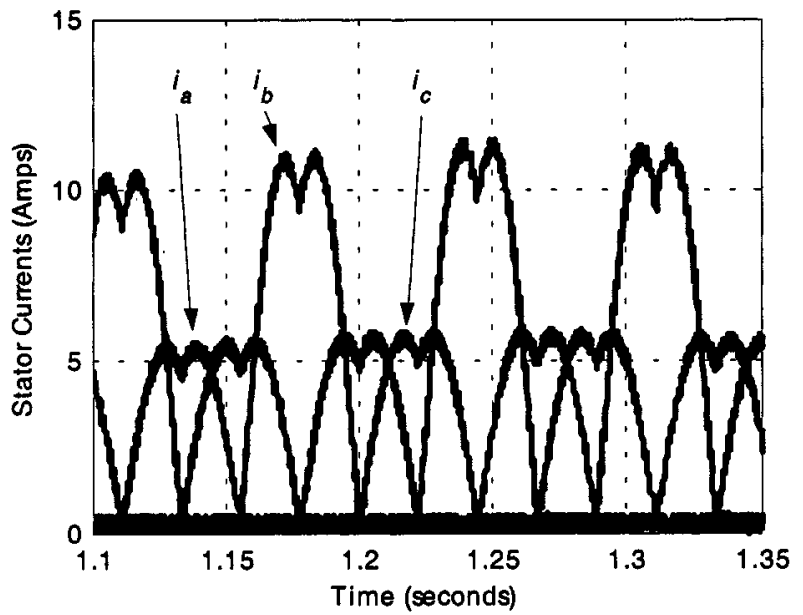

Fig. 8. Simulated phase currents.

tional ripple current source. In particular, the upper and lower link capacitor will each carry half of this current. The consequence of this current heating the capacitors through equivalent series resistance (ESR) depends greatly on the front-end converter design and PWM algorithm used [5].

\section{Simulation Results}

In order to investigate the proposed control method, simulations were performed using SIMULINK with postprocessing of data in MATLAB. The system simulated was one that would typically be found in an HVAC application. A 1-hp machine with the parameters given in the Appendix was used.

For the simulations, the motor was connected up to a fan load in which the torque load varies inversely proportional to the square of the speed up to the rated speed. The output frequency of the drive was fixed at $15 \mathrm{~Hz}$, producing a nominal speed of $900 \mathrm{r} / \mathrm{min}$. The motor currents were controlled with simple hysteresis regulators.

The simulations shown in Figs. 8-12 indicate that the proposed unidirectional currents supplied via a three-switch motor drive could be a useful control algorithm for low-cost applications requiring variable speed. The motor phase currents track the desired wave shape. The rotor currents are sinusoidal in na- 


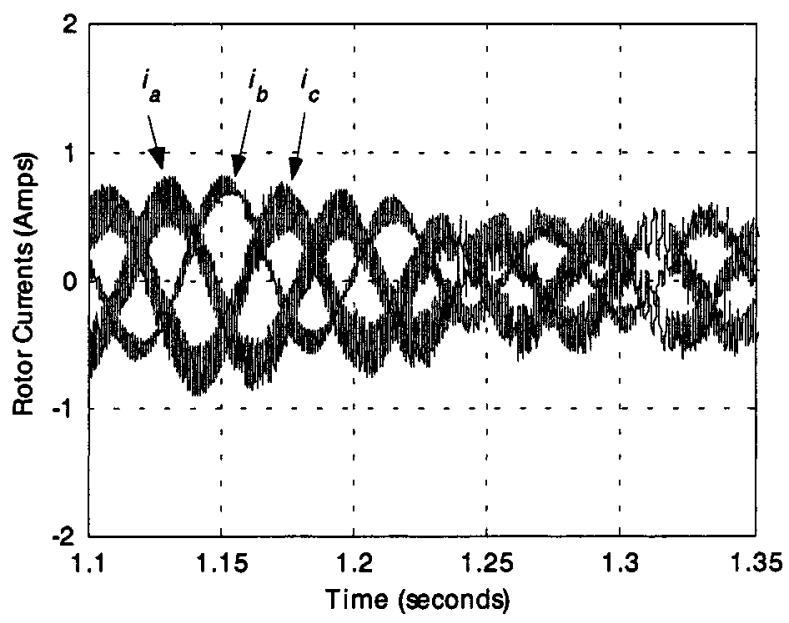

Fig. 9. Simulated rotor currents.

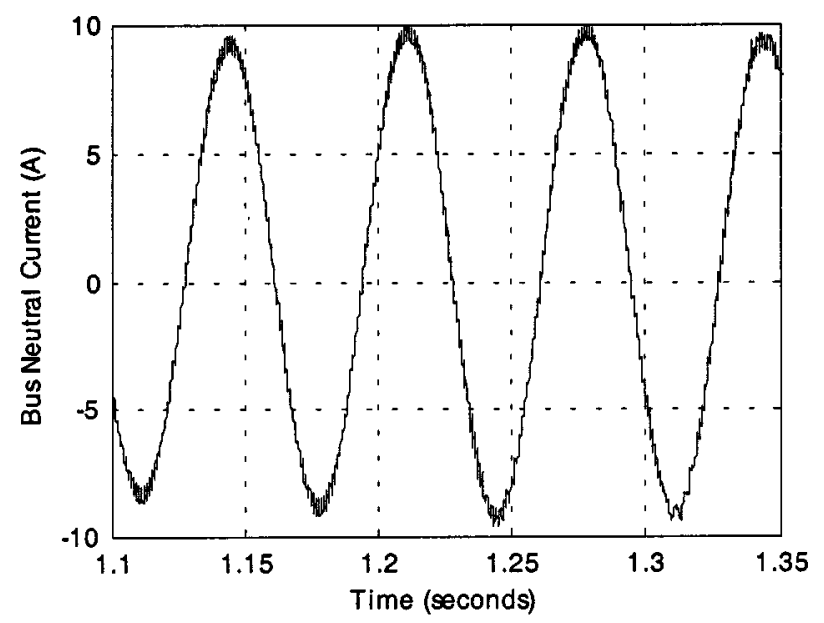

Fig. 10. Simulated bus neutral current.

ture as predicted and the motor experiences a smooth startup speed transient.

\section{EXPERIMENTAL RESULTS}

The proposed system has been implemented in hardware. Fig. 13 shows a control block diagram that was used for laboratory testing. For this proof of concept drive system, analog control hardware was used. This consisted of a programmable-memory-based lookup table to generate the reference wave for each of the phase currents. These were converted to analog signals via multiplying digital-to-analog converters. Both the frequency and the current amplitude set points were controlled manually. Op-amp-based hysteresis regulators were used to control the phase currents. Each of the phase currents was measured with a closed-loop Hall-effect current sensor. The phase- $b$ current was scaled by a factor of $1 / 2$ and reversed in polarity by changing the orientation and number of turns used in the current sensor. This served two purposes. First, it allowed for symmetrical current commands as shown in Fig. 1 which simplified the control circuitry while producing the required double amplitude current in phase $b$. Furthermore, it effectively made the hysteresis band for phase $b$

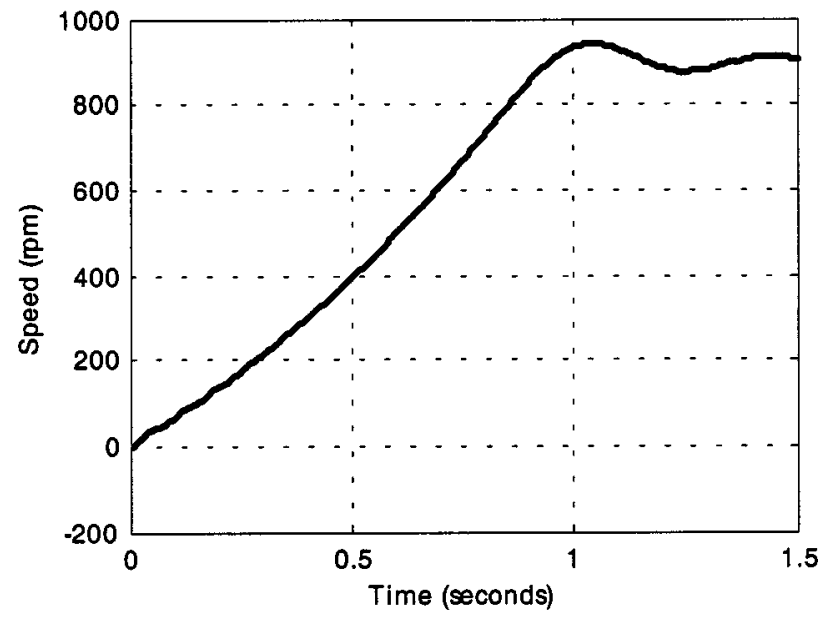

Fig. 11. Simulated motor speed showing startup.

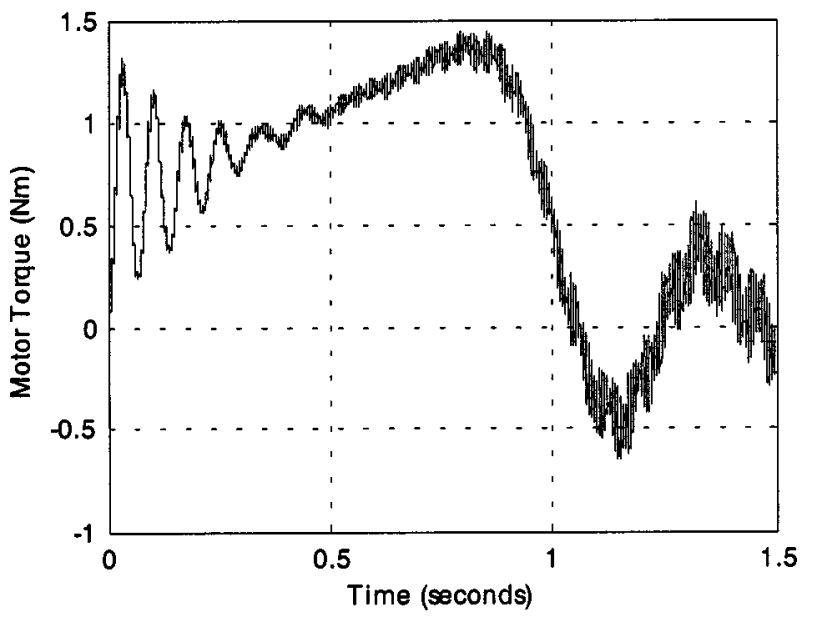

Fig. 12. Simulated motor torque showing startup.

twice as large as that of phases $a$ and $c$. This is desirable since it keeps the average switching frequency between the phases constant.

The voltage-doubler diode rectifier for this prototype was supplied by a single-phase 115 -Vac input, through an autotransformer. The autotransformer was used to solely to alleviate noise difficulties in the layout of the analog control circuitry used for this prototype and is not otherwise required. Due to the lack of a proper ground plane in control circuitry, operation at rated voltage could not be achieved.

The results presented here are for a fixed frequency of $15-\mathrm{Hz}$ excitation on the unloaded induction machine with the parameters given in the Appendix. The resultant speed was $892 \mathrm{r} / \mathrm{min}$.

The stator currents in Fig. 14 show the hysteresis band that is characteristic of that type of controller. There is some dc offset in each of the phases due to the offsets in the analog hardware used as the controller. The corresponding harmonic spectrum for the phase- $b$ current is shown in Fig. 15. It shows that the currents contain only triplen harmonics of the fundamental component.

Fig. 16 verifies that the neutral current is indeed a sinusoidal quantity as required for a stable dc link. The dc-link capacitor voltages shown in Fig. 17 show ripple frequencies at both half the supply frequency and the output frequency in addition to 


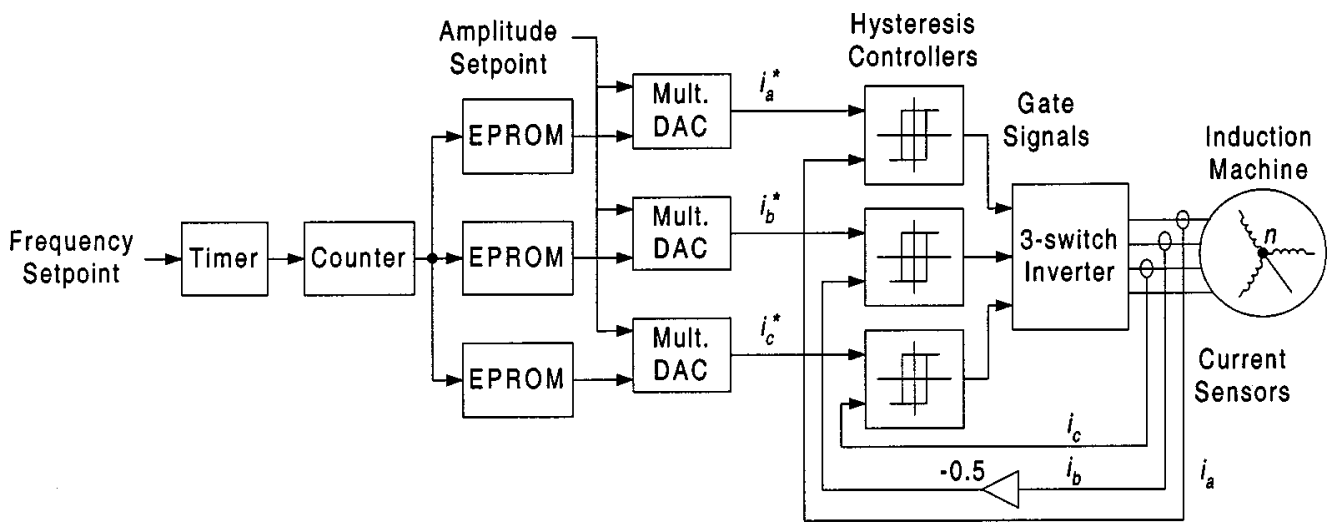

Fig. 13. Control block diagram of the experimental setup.

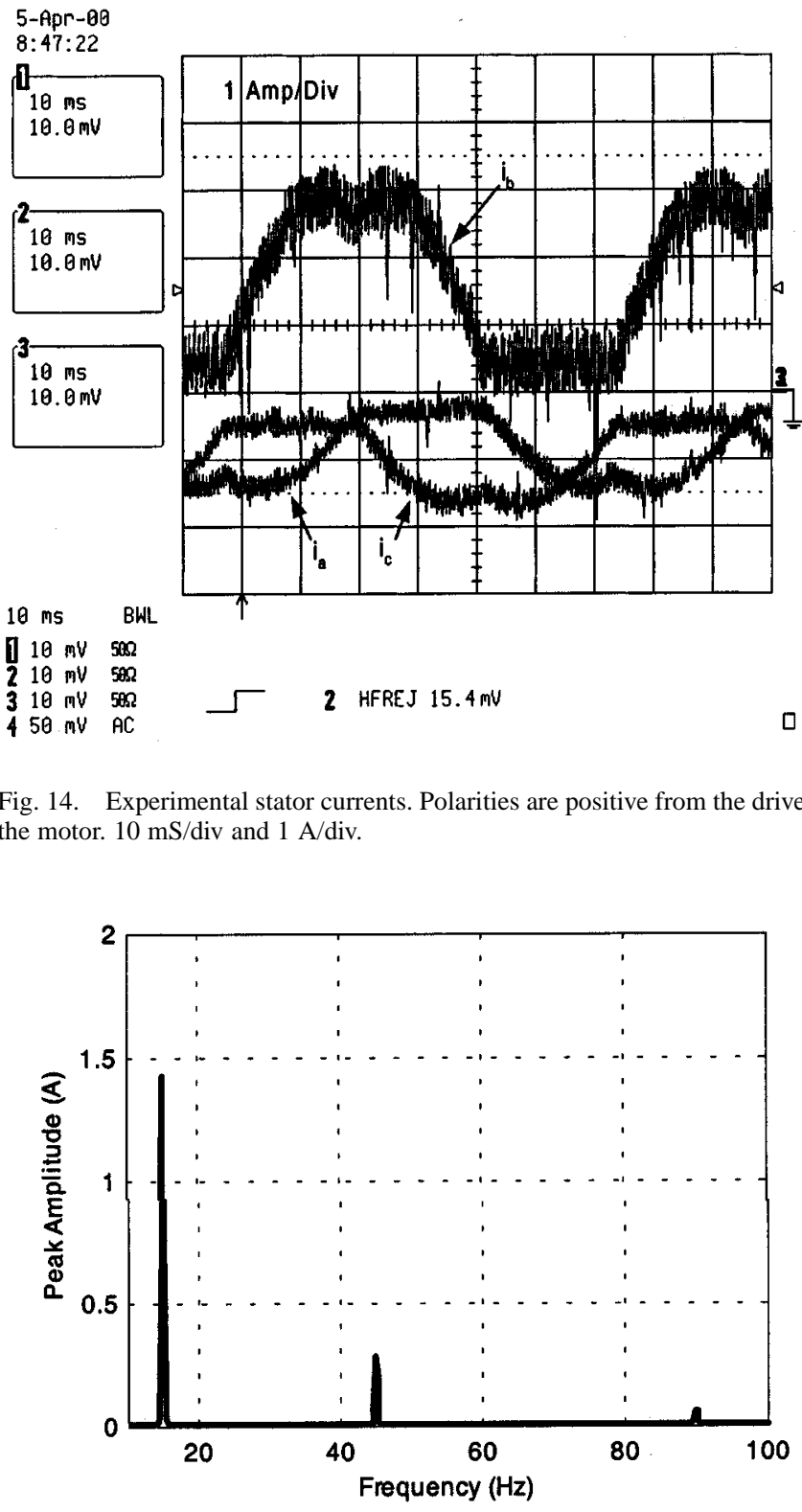

Fig. 15. Experimental harmonic spectrum of the phase $b$ stator current. Data obtained with a Hanning window, $10 \mathrm{rms}$ averages, and $f_{b}=0.25 \mathrm{~Hz}$.

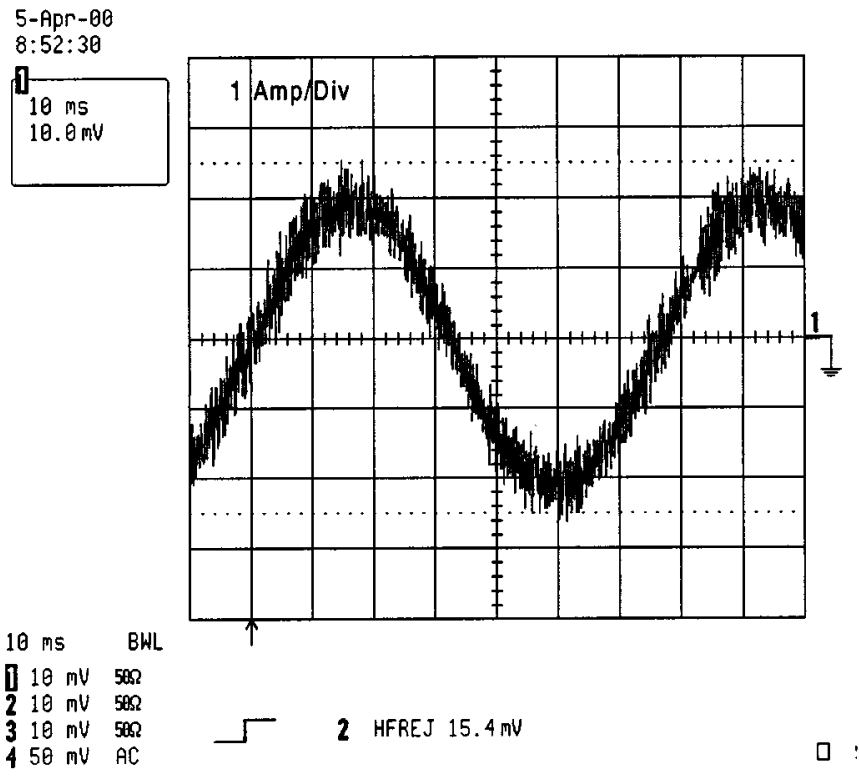

Fig. 16. Experimental stator neutral current. Polarity is positive from the drive to the motor. $10 \mathrm{mS} / \mathrm{div}$ and $1 \mathrm{~A} /$ div.

switching-frequency-induced ripple currents. This oscillogram further shows that the implementation and topology presented in this paper can be achieved with a passively controlled dc link.

\section{CONCLUSIONS}

This paper has proposed a novel current-source control method and drive topology for a three-phase induction machine. The currents are unidirectional in nature and can be produced with only one switch per phase. Both simulations and experimental laboratory results verified the method.

Some features of a motor drive implementing this control method as a low-cost alternative are the fact that it only requires three controlled switches and five diodes in a shoot-through-free leg structure, and one isolated power supply for the one high-side switch. As a result of the reduced parts count, the cost to produce this product should be significantly less than a comparable six-switch inverter. The lower cost will 


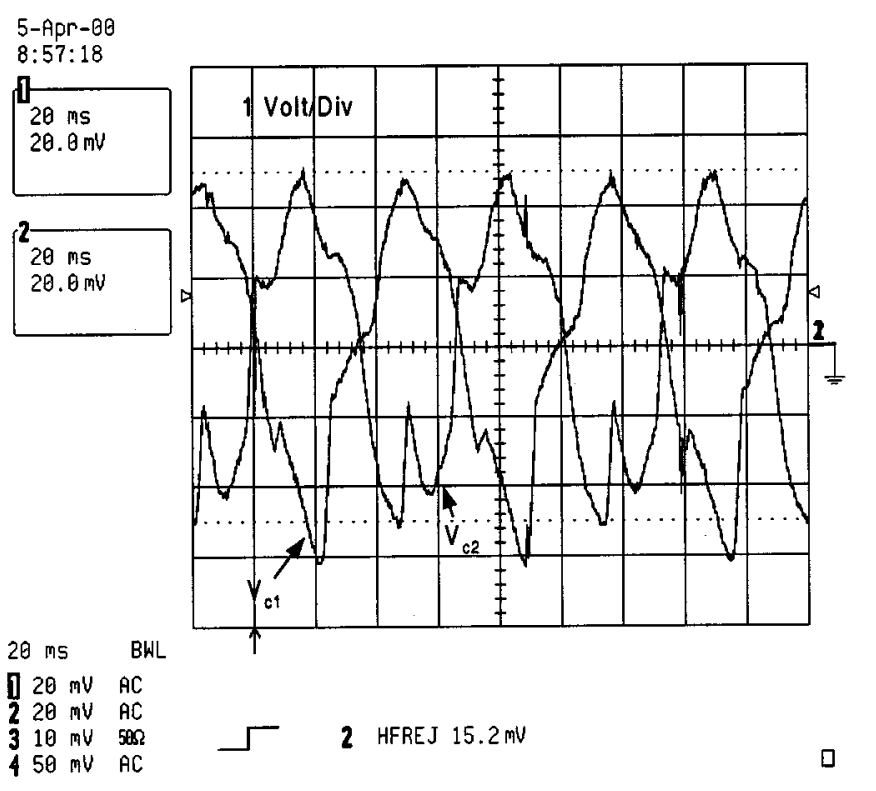

Fig. 17. Bus capacitor ripple voltages showing both a $30-\mathrm{Hz}$ and $15-\mathrm{Hz}$ component. $20 \mathrm{mS} / \mathrm{div}$ and $1 \mathrm{~V} / \mathrm{div}$. The reading is ac coupled. DC values are $V_{c 1}=40.5 \mathrm{~V}$ and $V_{c 2}=39.8 \mathrm{~V}$.

be appealing to industries that desire variable-speed operation to improve their products, but cannot tolerate the present day cost of the technology.

\section{APPENDIX MACHINE PARAMETERS}

The 115/230-V three-phase squirrel-cage-rotor dual-woundstator induction machine used for this paper for both the simulations and hardware experiments had the following characteristics when configured for high-voltage operation:

$$
\begin{array}{ll}
R_{1} \approx 2.0 \Omega, & R_{2} \approx 1.4 \Omega \\
L_{1} \approx L_{2} \approx 7.7 \mathrm{mH}, & L_{m} \approx 218 \mathrm{mH} \\
R_{m} \approx 465 \Omega, & \text { poles } \approx 2 \\
P_{\text {rated }} \approx 1 \mathrm{hp}, & f_{\text {rated }} \approx 87 \mathrm{~Hz} .
\end{array}
$$

\section{ACKNOWLEDGMENT}

The authors wish to acknowledge the motivation provided by the Center for Power Electronics Systems (CPES).

\section{REFERENCES}

[1] H. N. Hickok, "Adjustable speed-A tool for saving energy losses in pumps, fans, blowers, and compressors," IEEE Trans. Ind. Applicat., vol. IA-21, pp. 124-136, Jan./Feb. 1985.

[2] C.-T. Pan, T.-C. Chen, and C.-M. Hung, "A low cost voltage-fed current controlled inverter for induction motor drives," in Conf. Rec. IEEE Int. Symp. Industrial Electronics, 1993, pp. 434-439.

[3] H. W. Van Der Broeck and J. D. Van Wyk, "A comparative investigation of a three-phase induction machine drive with a component minimized voltage-fed inverter under different control options," IEEE Trans. Ind. Applicat., vol. IA-20, pp. 309-320, Mar./Apr. 1984.

[4] D. W. Novotony and T. A. Lipo, Vector Control and Dynamics of AC Drives. London, U.K.: Oxford Univ. Press, 1996.

[5] D. Rendusara, E. Cengelci, P. Enjeti, and D. C. Lee, "An evaluation of the DC-Link capacitor heating in adjustable speed drive systems with different utility interface options," in Proc. IEEE APEC'99, 1999, pp. 781-787.

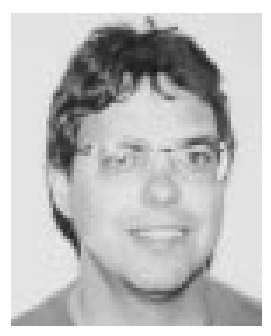

Brian A. Welchko received the B.S. and M.S. degrees in electrical engineering from Ohio University, Athens, in 1994 and 1996, respectively. He is currently working toward the Ph.D. degree at the University of Wisconsin, Madison.

While at the University of Wisconsin, he has been an intern with the Otis Elevator Corporation and also with General Motors-Advanced Technology Vehicles. His research interests are in the control of induction and interior permanent-magnet synchronous machines.

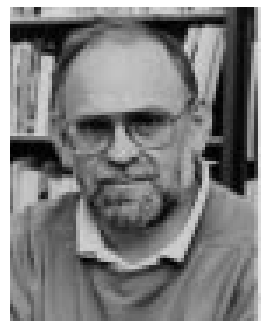

Thomas A. Lipo (M'64-SM'71-F'87) is a native of Milwaukee, WI. From 1969 to 1979, he was an Electrical Engineer in the Power Electronics Laboratory, Corporate Research and Development, General Electric Company, Schenectady, NY. He became a Professor of electrical engineering at Purdue University, West Lafayette, IN, in 1979 and, in 1981, he joined the University of Wisconsin, Madison, in the same capacity, where he is presently the W. W. Grainger Professor for power electronics and electrical machines.

Dr. Lipo has received the Outstanding Achievment Award from the IEEE Industry Applications Society, the William E. Newell Award from the IEEE Power Electronics Society, and the 1995 Nicola Tesla IEEE Field Award from the IEEE Power Engineering Societyfor his work. Over the past 30 years, he has served the IEEE in numerous capacities, including President of the IEEE Industry Applications Society. 